Disclosure of Interest: P. Mease Grant/research support from: Abbott, Amgen, Biogen Idec, BMS, Celgene Corporation, Genentech, Janssen, Eli Lilly, Novartis, Pfizer, Roche, UCB, Consultant for: Abbott, Amgen, Biogen Idec, BMS, Celgene Corporation, Genentech, Janssen, Eli Lilly, Novartis, Pfizer, Roche, UCB, Speakers bureau: Abbott, Amgen, Biogen Idec, BMS, Genentech, Janssen, Eli Lilly, Pfizer, UCB, D. Gladman Grant/research support from: AbbVie, Amgen, BMS, Celgene Corporation, Janssen, Novartis, Pfizer, and UCB, Consultant for: AbbVie, Amgen, BMS, Celgene Corporation, Janssen, Novartis, Pfizer, and UCB, E. Davenport: None declared, X. Zhou: None declared, B. Guerette Employee of: Celgene Corporation, L. Teng Employee of: Celgene Corporation, S. Kaura Employee of: Celgene Corporation, P. Nash Grant/research support from: Celgene Corporation

DOI: 10.1136/annrheumdis-2018-eular.3139 S. Kaura ${ }^{4}$, P. Nash ${ }^{5}{ }^{1}$ Swedish Medical Center and University of Washing School of Medicine, Seattle, USA; ${ }^{2}$ Krembil Research Institute, Toronto Western Hospital, Toronto, Canada; ${ }^{3}$ RTI Health Solutions, Research Triangle Park; ${ }^{4}$ Celgene Corporation, Summit, USA; ${ }^{5}$ University of Queensland, Brisbane, Australia

Background: Psoriatic arthritis (PsA) patients may experience disease manifestations across multiple domains and impaired functioning in daily activities at home and work. The phase 3b ACTIVE study is evaluating the efficacy of apremilast (APR) monotherapy in biologic-naïve subjects with active PsA who may have had exposure to 1 prior conventional DMARD.

Objectives: To assess work productivity through Week 104

Methods: Subjects were randomised (1:1) to receive APR $30 \mathrm{mg}$ BID or placebo (PBO). Subjects who did not improve by $\geq 10 \%$ in swollen and tender joint counts at Week 16 were eligible for early escape. At Week 24, all remaining PBO subjects were switched to APR. Work productivity and activity impairment were assessed at baseline (BL) and Week 16 using the 6-item, self-administered Work Productivity and Activity Impairment Questionnaire: Psoriatic Arthritis (WPAl:PsA). WPAI: PsA includes 4 subscale scores (Absenteeism, Presenteeism, Work Productivity Loss, and Activity Impairment), each ranging from $0 \%$ to $100 \%$; higher scores indicate greater impairment. Work-related subscales were evaluated only among employed subjects, while activity impairment was evaluated among all subjects, regardless of employment. Correlations were examined at Week 16 between WPAI:PsA subscale scores and the SF-36v2 domain scores for Physical Functioning (PF), Bodily Pain (Pain), and Vitality (VIT), as well as associations with ACR20 response. Improvement in work productivity was assessed through Week 104

Results: BL characteristics were similar between APR and PBO subjects with WPAI:PsA scores included in this analysis. At Week 16, APR significantly improved work productivity and the ability to carry out daily activities vs $\mathrm{PBO}$, with significantly greater mean improvements observed in the overall Work Productivity Loss $(\mathrm{p}=0.001)$ and Activity Impairment $(\mathrm{p}<0.001)$ scores (table 1$)$. Estimated mean change in the Absenteeism score was similar with APR vs PBO ( $p=0.679)$. By contrast, the Presenteeism score showed significant improvement with APR vs worsening with $\mathrm{PBO}(-10.8 \%$ vs $4.1 \% ; \mathrm{p}=0.002)$. At Week 16 , statistically significant correlations were observed between WPAI:PsA subscale scores (except Absenteeism) and the SF-36v2 domain scores for PF, Pain, and VIT, as were associations with ACR20 response. Among subjects randomised to APR at BL, improvements in Week 16 WPAI:PsA subscale score were generally maintained through Week 104 in those continuing APR.

\begin{tabular}{|c|c|c|c|c|}
\hline \multicolumn{5}{|c|}{ Improvements in WPAI:PsA Subscale Scores (\% Point) at Week 16} \\
\hline WPAI:PsA Subscale & $\begin{array}{l}\text { APR } 30 \mathrm{mg} \text { BID } \\
\text { LS Mean } \\
(95 \% \mathrm{Cl})\end{array}$ & $\begin{array}{c}\text { PBO } \\
\text { LS Mean } \\
(95 \% \text { CI) }\end{array}$ & $\begin{array}{c}\text { Treatment } \\
\text { Difference } \\
\text { (95\% Cl) }\end{array}$ & $P$ Value \\
\hline \multirow{2}{*}{ Presenteeism } & $n=39$ & $n=56$ & & \\
\hline & $-10.8(-17.8,-3.8)$ & $4.1(-1.7,9.9)$ & $-14.9(-24.1,-5.8)$ & 0.002 \\
\hline \multirow{2}{*}{ Work Productivity Loss } & $\mathrm{n}=40$ & $n=55$ & & \\
\hline & $-11.9(-18.8,-5.0)$ & $3.5(-2.4,9.4)$ & $-15.4(-24.5,-6.2)$ & 0.001 \\
\hline \multirow{2}{*}{ Activity Impairment } & $n=87$ & $n=103$ & & \\
\hline & $-11.8(-16.4,-7.1)$ & $-0.5(-4.7,3.8)$ & $-11.3(-17.6,-5.0)$ & $<0.001$ \\
\hline \multirow{2}{*}{ Absenteeism } & $n=40$ & $n=55$ & & \\
\hline & $-3.6(-5.9-13)$ & $-3.0(-4.9-1.0)$ & $-0.6(-3.7,24)$ & 0.679 \\
\hline
\end{tabular}

Abstract AB0946 - Figure 1

Results are from an analysis of covariance model, adjusted with BL WPAI: PsA subscale score, BL prednisone use (yes/no), and previous DMARD use (yes/no). LS mean is estimated using the observed margins of the covariates. WPAI: PsA scores were evaluated for subjects with values at both $\mathrm{BL}$ and Week 16. Absenteeism, Presenteeism, and Work Productivity Loss were evaluated only among employed subjects. Activity Impairment scores were evaluated among all randomised subjects with scores at BL and Week 16, regardless of employment status. $\mathrm{Cl}=$ confidence interval; $\mathrm{LS}=$ least square.

Conclusions: In biologic-naïve subjects with PsA, APR monotherapy contributed to an overall improvement in work productivity at Week 16, which correlated with SF-36v2 PF, Pain, and VIT scores and was associated with ACR20 response; improvements in WPAI:PsA subscale scores were generally maintained to Week 104.

\section{AB0947 IMPACT OF CLINICAL SPECIALTY SETTING ON DISEASE MANAGEMENT IN PATIENTS WITH PSORIATIC ARTHRITIS: RESULTS FROM A CROSS-SECTIONAL OBSERVATIONAL STUDY IN THE UNITED STATES}

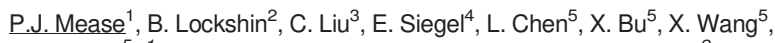
K. Douglas ${ }^{5}$. ${ }^{1}$ Swedish Med. Ctr. and Univ. of Washington, Seattle; ${ }^{2}$ US Dermatology Partners, Rockville; ${ }^{3}$ Bellevue Dermatology Clinic, Bellevue; ${ }^{4}$ Arthritis and Rheumatism Associates and Georgetown Univ., Rockville; ${ }^{5}$ AbbVie Inc, $N$ Chicago, USA

Background: Early diagnosis and effective treatment has been shown to decrease functional disability and structural progression in patients (pts) with psoriatic arthritis (PsA). ${ }^{1}$ However, factors that influence treatment management decisions are poorly understood.

Objectives: To evaluate the impact of clinical specialty setting on the manage ment of US pts with PsA.

Methods: LOOP was a multi-centre, cross-sectional observational study conducted across 44 sites in US. Adult pts with a suspected or an established diagnosis of PsA who were routinely visiting a rheumatologist (rheum) or a dermatologist (derm) were eligible to participate in this study. Each enrolled pt was assessed by both rheum and derm. The association between enrolling or diagnosing clinical specialty setting and time from symptom onset to PsA diagnosis and to different disease management steps were examined.

Abstract AB0947 - Table 1. Current Disease Activity and Disease Burden by Clinical Specialty in US Patients with PsA from LOOP Study

\begin{tabular}{|c|c|c|c|}
\hline Measure $^{a}$ & $\begin{array}{l}\text { Rheum } \\
(\mathrm{N}=366)\end{array}$ & $\begin{array}{c}\text { Derm } \\
(\mathrm{N}=147)\end{array}$ & P-value * \\
\hline TJC68 & $8.2(10.8)$ & $9.9(10.3)$ & .095 \\
\hline SJC66 & $3.4(6.4)$ & $4.3(6.0)$ & .154 \\
\hline DAS28 (CRP) & $3.2(1.5)^{b}$ & $4.2(2.0)^{c}$ & .095 \\
\hline DAS28 (ESR) & $3.1(1.6)^{d}$ & $3.8(2.1)^{\mathrm{e}}$ & .192 \\
\hline Enthesitis based on LEI & $1.0(1.6)$ & $1.5(1.8)$ & .005 \\
\hline Dactylitis count & $0.6(1.5)$ & $0.8(1.7)$ & .241 \\
\hline BASDAI (axial involvement) & $4.6(3.2)^{t}$ & $4.3(3.3)^{9}$ & .248 \\
\hline BSA (\%) & $5.0(10.9)$ & $8.1(14.5)$ & .024 \\
\hline Psoriatic nail count & $1.9(3.1)^{h}$ & $2.0(3.1)$ & .734 \\
\hline PASI & $3.0(5.1)^{i}$ & $5.5(7.9)$ & $<.001$ \\
\hline PtGA at the time of diagnosis & $6.7(2.7)^{k}$ & $5.9(3.1)^{\prime}$ & .003 \\
\hline PtGA during last visit & $4.7(2.9)^{\mathrm{m}}$ & $4.7(3.0)^{n}$ & .976 \\
\hline HAQ-DI & $0.9(0.7)$ & $0.7(0.7)$ & .057 \\
\hline SF1v2 PCS & $40.6(10.5)^{\mathrm{m}}$ & $41.8(10.3)$ & .244 \\
\hline SF12v2 MCS & $46.9(11.1)^{\mathrm{m}}$ & $47.9(11.9)$ & .361 \\
\hline DLQI & $5.4(5.9)^{\circ}$ & $7.8(7.4)$ & .001 \\
\hline
\end{tabular}

*P-value from two sample t-test: Rheumatologist vs Dermatologist.

${ }^{\text {a } A l l}$ data are presented as mean (SD) unless otherwise specified.

${ }^{\mathrm{b}} \mathrm{N}=40 ;{ }^{\mathrm{c}} \mathrm{N}=8 ;{ }^{\mathrm{d}} \mathrm{N}=67 ;{ }^{\mathrm{e}} \mathrm{N}=13 ;{ }^{\mathrm{f}} \mathrm{N}=361 ;{ }^{\mathrm{g}} \mathrm{N}=144 ;{ }^{\mathrm{h}} \mathrm{N}=321 ;{ }^{\mathrm{i}} \mathrm{N}=314 ;{ }^{\mathrm{j}} \mathrm{N}=145 ;{ }^{\mathrm{k}} \mathrm{N}=365$ ${ }^{\mathrm{I}} \mathrm{N}=138 ;{ }^{\mathrm{m}} \mathrm{N}=341 ;{ }^{\mathrm{n}} \mathrm{N}=65,{ }^{\circ} \mathrm{N}=361$.

$\mathrm{BSA}=$ body surface area with psoriasis; DAS28 $(\mathrm{CRP})=28$ joint disease activity score based on C-reactive protein; DAS28 (ESR)=DAS28 based on erythrocyte

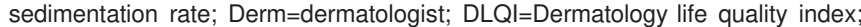
HAQ-DI=health assessment questionnaire - disability index; LEI=Leeds enthesitis index; MCS=mental component score; PASI=psoriasis area and severity index; PCS=physical component score; PGA=physician global assessment; $\mathrm{PsA}=$ psoriatic arthritis; $\mathrm{PtGA}=$ patient's global assessment of disease; Rheum=rheumatologist; SF12v2=Short form 12-item health survey version 2.0; SD=standard deviation; SJC66=swollen joint count, 66 joints; TJC68=tender joint count, 68 joints. 